\title{
強磁場環境における微量質量測定
}

\author{
成田九州男 ${ }^{\circledR * 1}$, 内田 三夫*1, 榊原 和久 ${ }^{* 2}$, 河原 紀男*3, \\ 渡部 新- $* 4$, 須田 俊- *4
}

\section{Weighing in a strong magnetic field}

\author{
Kusuo Narita, Mituo Uchida ${ }^{* 1}$, Kazuhisa SaKakibara ${ }^{* 2}$, Norio KaWAhara*3, \\ Yoshikazu Watabe and Shunichi SudA *4
}

\footnotetext{
${ }^{*}$ S School of Pharmaceutical Sciences, University of Shizuoka, 52-1, Yada, Shizuoka 422

*2 Sartorius K. K., 35-16 Daikan-cho, Higashi-ku, Nagoya 461

${ }^{* 3}$ Shimadzu Seisakusho, Kuwahara-cho 1, Nishinokyo, Nakagyo-ku, Kyoto 604

${ }^{*}{ }^{4}$ Nihon Siber Hegner K. K., 6-1-1, Heiwajima, Ohta-ku, Tokyo 143
}

(Received 22 August 1996, Accepted 20 September 1996)

It was studied whether micro balances can work properly and show accurate weighing results under a strong magnetic field. Although a nuclear magnetic resonance device (NMR) generates a very strong magnetic field, it is generally operated by the constant a power of a magnet. In the surroundings of a NMR device, electronic micro balances have shown accurate weighing results as long as they were properly operated and calibrated before use. In the case of mechanical micro balances, although a few $\mu \mathrm{g}$ changes were observed, they were correctable by calibration before use. At a place near to the mass spectrometer (MS), which always changes its magnetic power, micro balances showed slight changes in the weighing results. However, accurate weighing results were confirmed as long as a certain distance from the MS was maintained. Other disturbances caused by the magnetic field were observed while handling or moving a magnetic substance near to the micro balances. In such cases, a significant change in the weighing results or unstable results was observed.

Keywords : electronic micro balance; mechanical micro balance; NMR magnetic field; MS magnetic field; strong magnetic field.

\section{1 緒一言}

強磁場を有する核磁気共鳴装置（NMR）は有機化合 物の構造研究のためには強力な力を発揮するため広く普

*1 静岡県立大学薬学部: 422 静岡県静岡市谷田 $52-1$

*2 ザルトリウス (株) : 461 愛知県名古屋市東区代官町 36-16 第一富士ビル

*3 (株) 島津製作所: 604 京都府京都市中京区西の京桑原 町 1

*4 日本シイベルヘグナー(株): 143 東京都大田区平和島 6-1-1 東京流通センター
及し，使用される磁石も年ごとに強力な磁場を持つもの となっている. 同じ有機化合物の分析を目的とした化学 分析室は当然その近隣に配置され，そこに設置した微量 化学はかりが磁場によって測定異常現象を起こすことが 懸念される. 先に木村は質量分析計 (MS) の変動磁場 の周辺においてはかり皿が 1 個の非対象構造のもので 変化が認められたことを報告しているが定量性がそし く, 固定磁場については詳細が触れられていない1).

測定を行った分析室は地下 1 階, 地上 6 階建コンク リート建築の最上階にあり, 方位磁針を用いて磁場の方 
向を観察したところ, 隣室や上下の階に置かれた NMR のマグネットの影響のみでなく, 建物のはり. (梁) や化 学実験室のドラフトの磁気バルブや, 配電盤のリレー, 更に磁化した鉄製家具等が大きく磁気を乱していること が示された。 そのような環境において微量化学はかりが 正常に作動し, 正しい測定値が得られるかゼうかの性能 検査を行った。その結果は，長期間にわたって強い磁場 にさらされたはかりが受ける障害は不明であるが，短期 的には電子はかりは通常の手続きに従ってゼ口点を合わ せスパン調整を行った後使用すればなんら支障がなく， 機械式の直示はかりはゼ口点を合わせて使用すると $1 \mathrm{~g}$ 当たり数 $\mu \mathrm{g}$ の誤差を生じるが内蔵分銅の器差の範囲内 であり，そのまま使用して良いことが分かった．

\section{2 理 論}

電子はかりに与える磁場の影響について考察する. 磁 気力に関する Coulomb の法則より ${ }^{2)}$, ビームに固定し た可動コイルがはかりの内蔵する永久磁石から受ける力 $F_{\mathrm{i}}$ は次の式で与えられる。

$$
F_{\mathrm{i}}=k\left(m_{\mathrm{i}} m_{\mathrm{B}}\right) / r_{\mathrm{i}}^{2}
$$

但し， $m_{\mathrm{B}}:$ はかりのビームに固定された可動コイルの 磁場の強さ, $m_{\mathrm{i}}$ : 内蔵磁石の磁場の強さ, $r_{\mathrm{i}}$ : 内蔵磁石 と可動コイルとの距離, $k:$ 比例常数

可動コイルが漏えい（洩）磁場から受ける力 $F_{\mathrm{o}}$ は同 様に次式で与えられる。

$$
F_{\mathrm{o}}=k\left(m_{\mathrm{o}} m_{\mathrm{B}}\right) / r_{\mathrm{o}}{ }^{2}
$$

但し, $m_{\mathrm{o}}$ : 外部の漏洩磁場の強さ, $r_{\mathrm{o}}$ : 可動コイルまで の距離

可動コイルに両者の力が作用するとき, 式(1)と (2) より

$$
\begin{aligned}
F_{\mathrm{i}} / F_{\mathrm{o}} & =\left\{\left(m_{\mathrm{i}} m_{\mathrm{B}}\right) /\left(m_{\mathrm{o}} m_{\mathrm{B}}\right)\right\}\left(r_{\mathrm{o}}{ }^{2} / r_{\mathrm{i}}{ }^{2}\right) \\
& =\left(m_{\mathrm{i}} / m_{\mathrm{o}}\right)\left(r_{\mathrm{o}}{ }^{2} / r_{\mathrm{i}}{ }^{2}\right)
\end{aligned}
$$

ここで, $r_{\mathrm{i}}$ は $r_{\mathrm{o}}$ に比べて極めて小さいため $F_{\mathrm{i}} / F_{\mathrm{o}}$ は極 めて大となり, 漏洩磁場の影響はほとんど受けないこと が示される.

更に，電子はかりは使用に際して標準分銅によりスパ ン調整を行う.すなわち, 校正用の標準分銅を皿の上に 採り, 無荷重のときと同じ位置にビームを返すために必 要とした電気量を標準分銅の重量に読み替えて使用する ため, 調整後に環境の変化をもたらさない限り重量値は 校正用の標準分銅の重量を分割した值となる.

この二つの理由により, 電子微量はかりは強磁場にお
いても環境による変化が少なく安定な計測を行うことが できる.

\section{3 実験と結果}

\section{$3 \cdot 1$ 装 置}

漏洩磁場観測の対象にした装置は次のものである。装 備するマグネットの強さを参考に併記した ${ }^{3)}$.

日本電子製 核磁気共鳴装置 JMN-GSX500 $11.7 \mathrm{~T}$ 日本電子製 核磁気共鳴装置 JMN-GSX270 $6.3 \mathrm{~T}$ 日本電子製質量分析計 JMS-SX102 max $2.3 \mathrm{~T}$ 測定点における漏洩磁場の強さは F. W. Bell 製ガウ スメーターB Bll 640 にアキシャル型プローブを装着し て測定した. 又, 直径 $22 \mathrm{~mm}$ のネオジム磁石 (表面磁 束密度 $0.45 \mathrm{~T}$ ) を用いて,てんびん周辺での磁化物体 の移動の影響を調べた。

磁場の影響は，次の微量化学はかりについて観察し た。

電子はかり

Mettler MT-5 ひょう量 $5.1 \mathrm{~g}$ 読取限度 $0.001 \mathrm{mg}$ Sartorius MG-5 ひょう量 $5.1 \mathrm{~g}$ 読取限度 $0.001 \mathrm{mg}$ 島津製作所 AEM-5200

\section{晍垂式電子はかり}

$$
\text { ひよう量 } 5.2 \mathrm{~g} \text { 読取限度 } 0.001 \mathrm{mg}
$$

Sartorius S-4 ひよう量 $4.0 \mathrm{~g}$ 読取限度 $0.0001 \mathrm{mg}$ 機械式微量化学はかり

Mettler M5/SR ひょう量 $20 \mathrm{~g}$ 読取限度 $0.001 \mathrm{mg}$ Sartorius 2405 ひょう量 $30 \mathrm{~g}$ 読取限度 $0.001 \mathrm{mg}$ なお，重量測定には同一の $1 \mathrm{~g}$ 分銅を用い，はかりに 対する補正は行わなかった。

\section{$3 \cdot 2$ 固定磁場（NMR 周辺）環境におけるはかりの} 使用

$3 \cdot 2 \cdot 1$ 分析室における漏洩磁場の測定 使用実験 を行った分析室にはGSX500 と GSX270の二つの NMR が設置されており，GSX270 のマグネットの中心 より $3.5 \mathrm{~m}$, GSX500 のマグネットの中心より $7 \mathrm{~m}$ の位 置を測定点 No. 1 とし，GSX500 のマグネットに向か

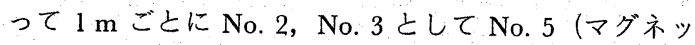
トの中心より $3 \mathrm{~m}$ ) まで測定点を設定し, 高さ $1 \mathrm{~m} の$ 位置で磁場の強さを測定した。機器の配置と漏洩磁場の 強さを Fig. 1に示した.

$3 \cdot 2 \cdot 2$ 電子はかりのスパン調整をしたときの重量変 化 通常, 電子はかりは標準分銅によってスパン調整 を行ってから使用する．装置によっては一定時間ごとに 自動的にスパン調整をするものもあり，電子はかり 4 
Table 1 Weight changes on $1 \mathrm{~g}$ weight with span adjustment

\begin{tabular}{lllll}
\multicolumn{1}{c}{ Microbalance $^{\text {a) }}$} & A & B & C & D \\
\hline No. of meas. points & 5 & 5 & 5 & 5 \\
No. of repeat & 3 & 3 & 3 & 3 \\
Mean values of weight $(1 \mathrm{~g}+\mu \mathrm{g})$ & & & \\
No. $1(0.10 \mathrm{mT})$ & 74.0 & 74.0 & 67.0 & 67.9 \\
No. $2(0.15 \mathrm{mT})$ & 74.0 & 74.0 & 67.7 & 66.2 \\
No. $3(0.22 \mathrm{mT})$ & 73.3 & 73.3 & 69.7 & 64.7 \\
No. $4(0.33 \mathrm{mT})$ & 73.7 & 72.0 & 68.7 & 64.8 \\
No. $5(0.52 \mathrm{mT})$ & 73.7 & 71.7 & 69.0 & 67.1 \\
Mean & 73.7 & 73.0 & 68.4 & 66.1 \\
Dispersion for point & 0.8 & 1.0 & 1.8 & 2.4 \\
Repeatability & & 0.4 & 1.2 & 0.1 \\
\hline
\end{tabular}

a) Microbalance: electronic balance for A, B, C, hunging pan-electronic balance for D. b) Standard deviation

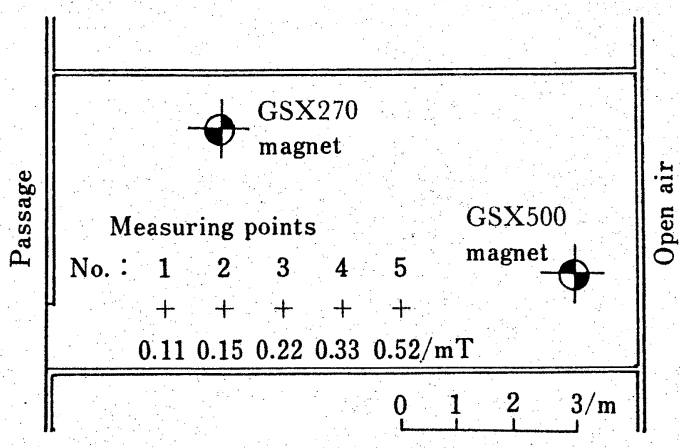

Fig. 1 Measuring points near the NMR

種類についてスパン調整の効果を検討した. 電子はかり を各測定点に静置して環境になじませた後，てんびんの 水平を調節しゼロ操作をした後スパン調整をした：毎回 ゼロ操作をした後 $1 \mathrm{~g}$ の分銅を 3 回測定した. 測定点 を移動するごとに同じ操作を行い, $1 \mathrm{~g}$ 分銅の重量を測 定した. その結果はTable 1 に示したように磁場の強 さには関係がなく，いずれの場合もはかりのばらつきの 範用内での重量変化を示した.

\section{$3 \cdot 2 \cdot 3$ 電子はかりのスパン調整をしないときの重量}

変化 電子はかりを移動した後スパン調整を行わなけ れば，移動前後の環境の変化が及ぼす影響が示される. 磁場の変化によるはかりの影響を観察するために，測定 点を移動後スパン調整を行わないで磁場強度の変化に伴 う $1 \mathrm{~g}$ 分銅の重量測定值の変化を測定した. 測定点 No. 1 に長時間てんびんを置いて環境になじませた後,てん びんの水平を調節しゼロ操作をした後スパン調整を行っ た. 毎回ゼ口操作をした後 $1 \mathrm{~g}$ の分銅を 3 回測定し, 測定点 No. 1 における分銅の重さを記録した。はかり
を測定点 No. 2 に移動して水平を調節しゼロ操作をし た後，スパン調整は行わず $1 \mathrm{~g}$ の分銅の重量を測定し た. 同様操作を測定点 No. 5 まで繰り返した。 その結 果はTable 2 に示した. はかり A は磁場が強くなると 表示スパンが縮小し，表示值が減少した。，一方はかり $\mathrm{B}$ は表示值が増加した。はかり $\mathrm{A}, \mathrm{B}, \mathrm{C}$ は上血式の電子 微量はかりであり，はかりによって磁場の影響の受け方 に差があることが分かったが, 実験例が少ないため, 機 種に特異的なものか個体の特性なのかは分からなかっ た. 懸垂式電子微量はかり Dでは磁場の強さの変化に 伴う表示值の変化は少なかった。機械式の微量はかり $\mathrm{E}, \mathrm{F}$ は数 $\mu \mathrm{g}$ の磁場の影響を受けた。しかしその測定 值の差は分銅の器差以下であり, 空気の浮力ゃ重力の補 正值に比して小さく，そのままで十分使用に耐えられる が, 設置場所においてはかりの感じの調整と分銅の補正 とを行えば全く障害が見られないことが確認された。

\section{$3 \cdot 3$ 変動磁場 (MS 周辺) 環境における電子はかり の重量変化}

はかりの重量表示值の変化が大きかったはかり A を, 磁場の強さが変動する MS の周辺に設置して測定值の 変化を観察した. 測定は最も大きく表示值が変化したは かり A を MS 周辺に設置し, 磁場の変化に伴う重量表 示值が変化する程度を調べた.その結果は Fig. 2 に示 した。測定はてんびんをマグネットから $50 \mathrm{~cm}$ 離れた ところに設置し, マグネットに最大出力を負荷したとき (漏洩磁場約 $0.03 \mathrm{mT}$ ) 数 $\mu \mathrm{g}$ の表示値の変化が認めら れた.MSの装置に並べて設置したときには漏洩磁場は 約 $0.01 \mathrm{mT}$ となりマグネットの影響は見られなかった. 従って，磁場をなるべく避けるような設置・使用をする かぎり, 表示值の変化は測定誤差の範囲内で納まると考 
Table 2 Weight changes on $1 \mathrm{~g}$ weight without span adjustment

\begin{tabular}{|c|c|c|c|c|c|c|}
\hline Microbalance $^{\text {a) }}$ & A & B & $\mathrm{C}$ & $\mathrm{D}$ & $\mathrm{E}$ & $\mathrm{F}$ \\
\hline No. of meas. points & 5 & 5 & 5 & 5 & 5 & 5 \\
\hline No. of repeat & 3 & 3 & 3 & 3 & 3 & 3 \\
\hline \multicolumn{7}{|c|}{ Mean values of weight $(1 \mathrm{~g}+\mu \mathrm{g})$} \\
\hline No. $1(0.10 \mathrm{mT})$ & 74.7 & 72.3 & 71.0 & 67.5 & 84.7 & 58.0 \\
\hline No. $2(0.15 \mathrm{mT})$ & 67.0 & 79.7 & 70.6 & 67.1 & 86.7 & 57.7 \\
\hline No. $3(0.22 \mathrm{mT})$ & 55.3 & 81.3 & 76.7 & 67.3 & 82.0 & 62.3 \\
\hline No. $4(0.33 \mathrm{mT})$ & 39.3 & 82.7 & 73.7 & 69.9 & 81.0 & 63.0 \\
\hline No. $5(0.52 \mathrm{mT})$ & -20.3 & 89.7 & 63.0 & 68.1 & 81.7 & 63.0 \\
\hline Mean values & 43.2 & 81.1 & 71.0 & 68.0 & 83.2 & 60.8 \\
\hline Dispersion for point $t^{b}$ ) & - & 10.1 & 5.5 & 1.2 & 4.1 & 4.7 \\
\hline Repeatability $^{\text {b) }}$ & 0.7 & 0.6 & 1.2 & 0.1 & 0.8 & 0.7 \\
\hline
\end{tabular}

a) Microbalance: electronic balance for A, B, C, hunging pan-electronic balance for D, mechanical balance for $\mathrm{E}$, F. b) Standard deviation.

Table 3 Limits of the stability for moving of magnet ${ }^{a)}$

\begin{tabular}{|c|c|c|c|c|c|c|}
\hline Microbalance & A & B & C & $\mathrm{D}$ & $\mathrm{E}$ & $\mathrm{F}$ \\
\hline Upper side $^{\text {b) }}$ & $80 \mathrm{~cm}$ & $35 \mathrm{~cm}$ & $20 \mathrm{~cm}$ & $25 \mathrm{~cm}$ & $100 \mathrm{~cm}$ & $10 \mathrm{~cm}$ \\
\hline Front side & 50 & 5 & 25 & 5 & 40 & 5 \\
\hline Right side & 90 & 20 & 20 & 25 & 40 & 5 \\
\hline Left side & 85 & 20 & 20 & 20 & 45 & 5 \\
\hline Back side & 60 & 30 & 20 & 20 & 40 & 5 \\
\hline
\end{tabular}

a) Neodimium magnet, $22 \mathrm{~mm}$ diameter, $1.7 \mathrm{~T}$. b) Distances from hausing of balance to magnet.

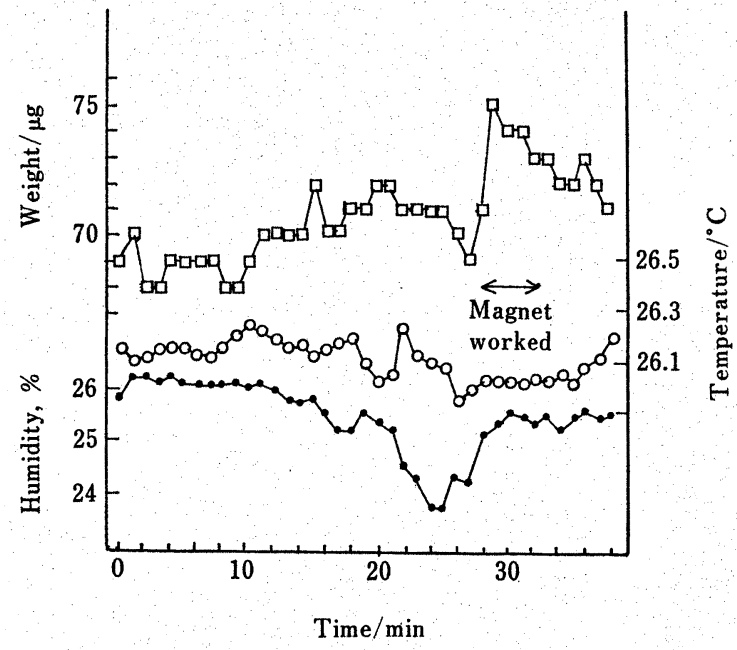

Fig. 2 Weight change of microbalance near the mass spectrometer

$\square$ : weight $/ \mu \mathrm{g} ; \bigcirc$ : temperature $/{ }^{\circ} \mathrm{C}$; : humidity, $\%$; Microbalance: A; Distance from MS magnet: $0.5 \mathrm{~m}$
えられる。

\section{3 •4 電子はかりの磁性体による静止点変化}

先に熱重量測定に用いる電子はかりが周辺に置かれた 鉄材等磁性体の移動に伴い静止点変化をすることを報告 したが4), 今回対象とした電子はかりでは周辺に置いた 鉄材を移動させることによる静止点変化は見られなかっ た.しかし, 磁化したピンセットの操作等による静止点 変動はかなり大きく見られたため, ネオジム磁石を動か して磁束方向を変化させながらてんびんに近付け, 静止 点変化を起こす距離の限界を調べた。その結果は Table 3 に示した. Table 2 において重量変化の大きく現れた はかりでは当然遠くに置かれた磁石にも反応した。個々 のはかりについて観察すると, 電子はかりのマグネット は八ウジングの後のほうにあることからはかり皿のある 前側は比較的影響が少ないことが分かり, 更にハウジン グの大きいはかりでは影響を受けにくいことが示され た. 微量はかりの取り扱いにおいては, 磁化したドライ バーやピンセットのてんびん室への持ち込みは避けなけ ればならないが, 風防, 間仕切り等は意外に磁化しやす。 
く，分析室においてはマグネット付きの時計や画びょう 類を使用しない配慮が必要である.

ひょう量が $1 \mathrm{~g}$ 以上, 感量が $0.001 \mathrm{mg}$ 以下の微量電 子はかり, 懸垂式微量電子はかり, 機械式の微量はかり について強磁場環境における使用実験を行った。そ結 果は, 電子はかりについては磁場の影響を受けやすい機 種も見られたが, NMR のような固定磁場の装置の周辺 においてはスパン調整をして測定すれば正しい值が得ら れることが分かった．機械式の微量はかりにおいては測 定值に変化が見られたが分銅の公差以下であり，更に使 用場所に設置後感じの調整と分銅の補正を行えば正確な 測定值が得られる，すなわち，いずれの微量はかりも一 般的に設置環境について考えるとき, 温度・湿度の変化 を避けその中で分銅補正や感じの調整，スパン調整等の 手続きは必要であり, 磁場についても固定磁場であれば 設置環境の一部として微量はかりによる計測には影響を
及ぼさないものと考えられる。

但し，磁場を含む環境の変化や磁性物質の移動等, 変 化する磁場に対して微量はかりは無防備であり, 正確な 表示値を得るためには十分な配慮が必要である.

磁場の測定及び磁気に対する御指導をいただいた日本電 子データム(株)久保田恒久氏に厚く御礼申し上げます。

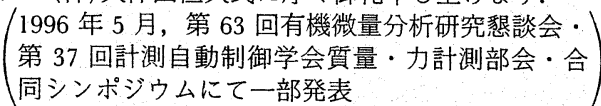

\section{文献}

1) 木村栄作: 計量管理, 24, 500 (1975).

2) 岡本祥一: “磁気と材料”, 化学 One Point 23 , 谷 口雅男, 妹尾 学編, p. 86 (1991), (共立出版).

3）日本電子(株) : 超伝導マグネットインストラクシ ヨン, p. 1 (1989).

4) K. Narita, T. Miyahara, K. Yamamoto, H. Kitamura, M. Uchida, M. Momota: Netsu Sokutei, 20, 198 (1993).

\section{要 旨}

核磁気共鳴装置 (NMR) 周辺の強磁場環境において, 微量化学はかりが正常に作動し正しい測定值 が得られるかどうかを検討した．通常電子はかりは使用に先立ってゼロ点を合わせ，スパン調整を行っ てから使用する.NMR は強力な磁場を備え漏洩磁場も強いが固定した磁場を示すため, はかりの調整 が行われた後に磁場の変動がなければ正確な測定值が得られた。調整後移動したり，質量分析計のよう に磁場の出力が変動するものの周辺では測定值の変化が観察されたが, 調整後移動したり極端にマグネ ットに接近して設置しないかぎり，測定值に影響を受けることはなかった，機械式の微量はかりでは NMR の強磁場において数 $\mu \mathrm{g}$ の重量誤差が見られた，測定值に影響を与えるほかの原因には，はかり の周辺で磁化した物体を取り扱ったり移動することが挙げられ，この場合は測定值の変化や異常値が示 される. 